\title{
O INVESTIMENTO NA FORMAC̣ÃO DO CIDADÃO DO FUTURO: A ALIANCCA ENTRE ECONOMIÁ E EDUCAÇÃO INFANTIL COMO ESTRATÉGIA DA GOVERNAMENTALIDADE CONTEMPORÂNEA
}

\author{
Rodrigo Saballa de Carvalho* \\ Universidade Federal da Fronteira Sul (UFFS), Erechim - RS, Brasil
}

RESUMO: $\mathrm{O}$ artigo apresenta resultados de uma pesquisa que, a partir dos estudos de Michel Foucault, problematiza os modos como as crianças são significadas como capital humano em documentos produzidos por analistas econômicos, os quais servem de referência aos países em desenvolvimento para a proposição de políticas de Educação Infantil. Para tanto, são tomados como materialidade investigativa os seguintes documentos produzidos pelo Banco Mundial: 1) Como investir na primeira infância: um guia para a discussão de políticas e a preparação de projetos de desenvolvimento da primeira infância, 2) Educação Infantil: programas para a geração mais importante do Brasil. $\mathrm{Na}$ análise opera-se com a noção de governamentalidade enquanto ferramenta conceitual. É possível, então, inferir que o argumento central presente nos documentos é o de que intervenções educacionais precoces qualificam o capital humano da criança pobre e elevam a produtividade do futuro trabalhador, constituindo, assim, o cidadão do futuro.

Palavras-Chave: Educação Infantil. Economia. Governamentalidade. Capital humano. Risco.

\section{INVESTMENT IN EDUCATING CITIZENS OF THE FUTURE: THE ALLIANCE BETWEEN ECONOMY ANDEARLY CHILDHOOD EDUCATION AS A CONTEMPORARY GOVERNMENTALITY STRATEGY}

ABSTRACT: This paper presents results of a research that, based on Michel Foucault's studies, discusses the ways in which children are signified as human capital in documents produced by economic analysts, which serve as reference to developing countries for the proposition of Early Childhood Education policies. In that regard, the following documents produced by the World Bank are taken as investigative material: 1) Como investir na primeira infância: um guia para a discussão de políticas e a preparação de projetos de desenvolvimento da primeira infância;

http://dx.doi.org/10.1590/0102-4698144920

"Doutor em Educação pela Universidade Federal do Rio Grande do Sul (UFRGS), Pós-Doutor em Educação pela Universidade Federal de Pelotas (UFPEL). Professor Pesquisador da Universidade Federal da Fronteira Sul (UFFS). Membro do Grupo de Pesquisa: Crianças, Infâncias e Culturas (CIC - UFPEL). E-mail: < rsaballa@terra.com.br >. 
2) Educação Infantil: Programas para a Geração Mais Importante do Brasil. In the analysis, governmentality is considered as a conceptual tool. It is then possible to infer that the central argument present in the documents is that early educational interventions qualify poor children's human capital and elevate future worker's productivity, thus constituting the citizen of the future.

Keywords: Early Childhood Education. Economy. Governmentality. Human capital. Risk.

\section{CONSIDERACְÕES INICIAIS}

Atualmente ressonâncias de pesquisas do campo da economia vêm se desdobrando em orientações para a operacionalização de políticas para o Desenvolvimento na Primeira Infância (DPI) ${ }^{1}$. Essas políticas se focam no desenvolvimento de habilidades que objetivam a formação de um indivíduo produtivo e empreendedor de si mesmo - o cidadão do futuro. Por esse motivo, conforme Viana (2012), crianças oriundas de famílias de baixa renda têm sido entendidas como um capital no qual se deve investir, tendo em vista o desenvolvimento de habilidades que as capacitem para uma atividade laboral futura no contexto de trabalho competitivo que regula o Estado neoliberal contemporâneo.

Nas análises econômicas, a infância que está à margem das condições de vida consideradas produtivas pelo Estado é tomada como um risco social que demanda intervenção, acompanhamento e avaliação (PENN, 2002). Marquez (2006) e Bueno (2010) argumentam que tal proposição está envolvida em um processo de produção da infância no interior das regras do discurso econômico. As autoras ainda afirmam que, no contexto das orientações de organizações internacionais para a proposição de políticas de DPI, é possível perceber uma progressiva aliança entre economia e Educação Infantil como estratégia de investimento no capital humano ${ }^{2}$ de crianças pobres, tendo em vista $\mathrm{o}$ desenvolvimento dos países em desvantagem econômica.

Diante dessa lógica, Shore e Wright (1997) apontam que a alegação dos analistas econômicos de que é importante investir na primeira infância tem colocado acento na vulnerabilidade das crianças pobres. Isso ocorre principalmente no que tange aos riscos de que essas crianças se tornem adultos improdutivos. Há também a necessidade de promoção de um conjunto de ações que permita aos países se prevenirem desses riscos, fazerem frente a eles e reduzirem os danos financeiros que podem ser causados pela falta de práticas que potencializem o desenvolvimento das crianças para uma vida adulta economicamente produtiva. 
Desse modo, o artigo apresenta os resultados de uma pesquisa que objetivou problematizar os modos como as crianças estão sendo consideradas nos cálculos do governo, ao serem significadas em dois documentos produzidos por analistas econômicos, endereçados a gestores públicos. Tais documentos têm servido como referência aos países em desenvolvimento para a proposição de políticas de Educação Infantil. Partindo dessa discussão, opera-se, analiticamente, com os conceitos de governamentalidade (GORDON, 1991; DEAN, 1999; FOUCAULT, 2008a, 2008b; FIMYAR, 2009), capital humano (LÓPEZ-RUIZ, 2007; GADELHA, 2009) e risco (O’MALLEY, 1996; LUPTON, 1999; LUHMANN, 2002; LEMKE, 2014), evidenciando as relações de poder que integram esses processos.

Constituem-se como materialidade investigativa ilustrativa da aliança entre economia e Educação Infantil os seguintes documentos produzidos pelo Banco Mundial ${ }^{3}:$ 1) Como investir na primeira infância: um guia para a discussão de políticas e a preparação de projetos de desenvolvimento da primeira infância (NAUDEAU et al., 2011) ${ }^{4}$; 2) Educação Infantil: programas para a geração mais importante do Brasil (EVANS; KOSEC, 2011) ${ }^{5}$. Ambos os documentos foram selecionados pelo fato de focalizarem a Educação Infantil e de divulgarem e promoverem uma gramática de práticas sobre como potencializar o desenvolvimento de crianças pobres.

Com base na leitura do material, foi realizada uma análise das práticas políticas existentes nele (GORDON, 1991; MILLER, 2012), destacando os modos pelos quais se intensificam os investimentos políticos sobre as crianças a partir de uma expertise de cunho econômico. Esses investimentos são alicerçados discursivamente na noção de desenvolvimento infantil que posiciona a população infantil como um espaço de produção de capital humano (MARQUEZ, 2006).

A análise ocorreu partindo do mapeamento das estratégias de governamento ${ }^{6}$ presentes nos documentos selecionados. As estratégias de governamento, conforme Dean (1997, 1999), são identificadas sempre que existe um campo relativamente estável de correlação de visibilidades, mentalidades, tecnologias e agências que constituem um ponto de referência para a problematização.

Nesse sentido, a governamentalidade foi tomada como uma ferramenta conceitual (FIMYAR, 2009) que permitiu problematizar o funcionamento das estratégias de governamento perceptíveis nos materiais, assim como os efeitos que estas produzem sobre a vida da população (GORDON, 1991). Essa problematização também possibilitou analisar a forma como a vida das crianças e de suas famílias tem sido convertida em objeto e objetivo de governamento. 
Assim, foi possível evidenciar como uma racionalidade política específica ${ }^{7}$, fundamentada na conjunção do campo da Economia e da Educação Infantil, se relaciona com o funcionamento de estratégias que incidem sobre os sujeitos, no intuito de conduzir suas condutas e de promover processos de subjetivação (ROSE, 2013).

A leitura dos documentos resultou na definição de um eixo temático e de três unidades de análise. O eixo temático definido foi "estratégias de gestão de riscos e produção de capital humano", pelo fato de tais aspectos constituírem a tônica do material. Com base no eixo, foram evidenciadas três unidades de análise: 1) A gramática da expertise econômica; 2) O investimento em DPI como lema da prontidão escolar e da prontidão para a vida; 3) Os programas de DPI e a gestão de riscos.

A partir da definição das unidades e do trabalho com a noção de governamentalidade (GORDON, 1991; DEAN, 1999; FOUCAULT, 2008a, 2008b), foi possível analisar como e com que efeitos as estratégias de governamento veiculadas pelos documentos se relacionavam, produzindo "verdades" sobre os modos considerados adequados de investir no desenvolvimento das crianças, tendo em vista retornos econômicos. A noção de governamentalidade foi utilizada como uma ferramenta conceitual (FIMYAR, 2009), através da qual foi possível observar que as estratégias preconizadas pelos analistas econômicos se fundamentam no argumento de que o investimento no capital humano de crianças pobres possibilita a formação de pessoas mais produtivas. Nessa linha de pensamento, haveria efeitos diretos no aumento de emprego, renda e escolaridade e na redução de riscos, como o número de gestações indesejadas, de atitudes violentas, entre outros aspectos que trazem prejuízos ao desenvolvimento dos países (HECKMAN, 2006, 2008; BARROS, 2011).

Considerando essa apresentação inicial, convém destacar que o artigo está organizado em cinco seções. Na primeira seção, é apresentado o conceito de governamentalidade. $\mathrm{Na}$ segunda, terceira e quarta seções, são explicitadas as análises do material, nas quais é focalizada a gramática da expertise econômica; o lema da prontidão escolar e da prontidão para a vida a partir do investimento em DPI; e gestão de riscos. Por fim, na última seção, são apontadas as considerações finais.

\section{A GOVERNAMENTALIDADE COMO FERRAMENTA CONCEITUAL}

Foucault (2008b) evidenciou os modos pelos quais o poder político ocidental, ao ser exercido por meio de alianças entre diversas autoridades, progressivamente assumiu a tarefa de governamentalizar 
a sociedade. Tal pesquisa ocorreu por meio da apresentação dos deslocamentos da pastoral cristã (o Estado de justiça nascido em uma territorialidade do tipo feudal, que corresponderia a uma sociedade da lei) à sociedade de regulamento e disciplinas (o Estado administrativo, nascido em uma territorialidade do tipo fronteiriça, e não mais feudal, nos séculos XV e XVI), e desta à sociedade de polícia (Estado de governo que já não é definido por sua territorialidade, pelo espaço ocupado, mas pela população), controlada por dispositivos de segurança.

Ao enfocar o conceito de governamentalidade, Foucault (2008b) demonstrou que a preocupação com a arte de governar começou a ocupar espaço no início do século XVI, emergindo definitivamente no fim do século XVIII, quando se consolidou a Razão de Estado (DEAN, 1999). A partir desse período, a governamentalidade passou a se relacionar a múltiplos aspectos, como o governamento de si (estoicismo), o governamento das almas (pastoral), o governamento das crianças (pedagogia) e o governamento dos Estados pelos príncipes, não se referindo mais apenas à gestão de um território, mas à de uma coletividade definida como população. Nesse sentido, é oportuno apresentar a acepção foucaultiana do conceito de governamentalidade, no intuito de pensá-la enquanto ferramenta para análise dos documentos selecionados:

[...] conjunto constituído pelas instituições, os procedimentos, análises e reflexões, os cálculos e as táticas que permitem exercer essa forma bem específica, embora muito complexa, de poder que tem por alvo principal a população, por principal forma de saber a economia política e por instrumento técnico essencial os dispositivos de segurança. Em segundo lugar, por governamentalidade entendo a tendência, a linha de força que, em todo o Ocidente, não parou de conduzir, desde há muito, para a preeminência desse tipo de poder que podemos chamar de governo sobre todos os outros - soberania, disciplina - e que trouxe, por um lado, o desenvolvimento de toda uma série de aparelhos específicos de governo e, por outro lado, o desenvolvimento de toda uma série de saberes. Enfim, por governamentalidade creio que se deveria entender o processo, ou antes, o resultado do processo pelo qual o Estado de justiça da Idade Média, que nos séculos XV e XVI se tornou o Estado administrativo, viu-se pouco a pouco governamentalizado (FOUCAULT, 2008b, p. 143-144).

Esse sentido político atribuído à governamentalidade possibilita pensar como uma racionalidade específica do nosso tempo - a proposição de políticas para o investimento no capital humano de crianças pobres - organiza determinadas formas de conduzir as condutas dos sujeitos e das populações, promovendo o planejamento de estratégias relativas à gestão de fatores de risco. Essas estratégias 
são planejadas sob a justificativa de que o risco social, além de gerar altos custos para o país, torna uma parcela da população dependente da tutela do Estado para resolver seus problemas (LUHMANN, 2002).

Corroborando o argumento, Merrien (2008) afirma que as políticas sociais contemporâneas podem ser vistas enquanto exemplos de como o Estado passou a ser governamentalizado, já que elas fazem parte de recomendações vindas do mercado e de seus mecanismos de produção de conhecimento e verdade através das mais variadas formas de racionalidade e cálculo. Nesse sentido, os excertos dos documentos a seguir podem ser vistos como ilustrativos do argumento apresentado pelo referido autor:

\footnotetext{
Intervenções no DPI são essenciais para aumentar a produtividade do Brasil como um todo e para proporcionar oportunidades iguais a toda a população. Esses programas beneficiam mais os pobres do que os demais e os pobres precisam muito desses benefícios. Intervenções na educação desempenham um papelchave. As creches e as pré-escolas oferecem oportunidades para a estimulação cognitiva e não cognitiva e para o desenvolvimento. Essas oportunidades podem ajudar as crianças no sucesso acadêmico e no acesso ao mercado de trabalho futuro (EVANS; KOSEC, 2011, p. 3).

As habilidades desenvolvidas na infância formam a base para o aprendizado futuro e o sucesso no mercado de trabalho. O DPI aumenta a capacidade da criança de aprender, de trabalhar em grupo, de ser paciente e de desenvolver outras habilidades que são a base da aprendizagem formal e da interação social no ambiente escolar e fora dele (NAUDEAU et al., 2011, p. 15).
}

Conforme destacado nos documentos, a primeira infância de crianças pobres é significada nas análises econômicas como um espaço de risco que precisa ser conhecido e administrado por meio de programas governamentais. É o caráter calculável da população infantil que enseja a possibilidade de intervenções dirigidas aos problemas que afetam a vida das crianças. Isso ocorre, conforme O’Malley (1996), Lupton (1999) e Lemke (2014), porque a noção de risco e as práticas dela derivadas estão associadas à sociedade de segurança, a qual permite inserir determinados fenômenos dentro de uma série de acontecimentos prováveis.

Em relação a fenômenos como o desenvolvimento de habilidades na primeira infância, por exemplo - associado por Cunha et al. (2006) e Cunha e Heckman $(2007,2008)$ a condições nutricionais, ambiente familiar, nível de escolaridade da mãe, qualidade das intervenções recebidas na creche, dentre outros -, é realizado um cálculo de custos. É esse cálculo que permite prescrever as condutas adequadas e orientar medidas objetivando a minimização dos riscos de que as crianças pobres não se desenvolvam satisfatoriamente. 
Esse tipo de governamentalidade se nutre fundamentalmente do risco da pobreza, do medo do desemprego e dos perigos da violência para poder disseminar-se o mais amplamente possível (O’MALLEY, 1996). Para obter êxito, tal arte de governar maneja os riscos, administra os medos e produz perigos, como será evidenciado a seguir.

À medida que crescem, as crianças que vivem na linha de pobreza provavelmente experimentarão baixo desempenho escolar, incluindo altas taxas de repetência e evasão, bem como altas taxas de fertilidade e de morbidade, que contribuem para a ineficiência e os altos custos nos setores da educação e da saúde. Elas também são mais propensas a ter baixa produtividade e renda, e a não prestar cuidados suficientes aos filhos, contribuindo para a transmissão intergeracional da pobreza; além disso, são menos suscetíveis de contribuir para o crescimento econômico do país (NAUDEAU et al., 2011, p. 17).

Há uma série de maneiras pelas quais o Brasil pode contribuir para a melhoria da qualidade do ensino infantil em áreas importantes. Primeiro, o Governo Federal pode desenvolver guias curriculares mais específicos, que forneçam atividades para as creches e pré-escolas. Em segundo lugar, o Brasil pode introduzir o monitoramento sistemático por meio do acesso a uma ferramenta padrão de observação. Terceiro, o Governo Federal pode fornecer diretrizes de licenciamento de normas mínimas de qualidade às quais os municípios devem se adaptar. Esse é um passo além das orientações existentes para a qualidade de creches: ele implica diretrizes mínimas de qualidade e orientação sobre como um programa de licenciamento seria empregado. Por fim, o Brasil pode incentivar municípios a fornecer recursos para a melhoria dos centros, com base em medidas observacionais de qualidade, bem como incentivos para bons centros (EVANS; KOSEC, 2011, p. 34).

Pode-se depreender da leitura que a governamentalidade se tornou o terreno comum das formas contemporâneas de racionalidade política, orientando, de acordo com Miller e Rose (2012), as tarefas dos governantes em termos de supervisão e maximização calculada das forças dos indivíduos desde a infância. Além disso, é evidente o imperativo de que sejam formados indivíduos, desde essa idade, com mais habilidades e flexibilidade para mudanças, de forma que possam se tornar adultos produtivos, participantes do jogo do consumo e empreendedores de si mesmos - cidadãos do futuro (LÓPEZ-RUIZ, 2007). É a infância pobre, aquela que está à margem das condições de vida consideradas produtivas pelo Estado, que representa, do ponto de vista econômico, um risco social.

Por isso, a população infantil pobre é o foco das ações de governo, implicando investimentos que buscam priorizar esforços em direção a racionalidades de governamento da conduta das crianças e das pessoas envolvidas com seu cuidado e educação. Nessas bases, as análises dos economistas partem de pressupostos universais sobre o desenvolvimento infantil, construindo suas argumentações a partir 
de um modelo universal que toma como parâmetro as crianças das camadas médias e altas da sociedade (WONG, 2008; GOUVÊA, 2010). É com base nesse modelo que são planejados programas de Educação Infantil fundamentados em uma expertise econômica.

\section{A GRAMÁTICA DA EXPERTISE ECONÔMICA}

O impacto da educação sobre o desenvolvimento infantil vem sendo amplamente discutido pela literatura econômica (ARAÚJO, 2011; VIANA, 2012). Partindo das contribuições de áreas distintas, como as neurociências e a psicologia cognitiva, as pesquisas na área econômica sobre o impacto da Educação Infantil constituem uma expertise sobre as crianças oriundas de famílias de baixa renda. Essa expertise tem sido amplamente difundida por meio de pesquisadores como James Heckman ${ }^{8}$ (CUNHA; HECKMAN, 2009, 2011; HECKMAN, 2006, 2008; HECKMAN; MASTEROV, 2004), que defendem a eficiência econômica da Educação Infantil e sua importância como solução dos diversos problemas de ordem econômica, política e social que afetam os países em desenvolvimento.

Em tal contexto, a produção de conhecimentos decorrente dessa expertise desempenhaumpapel estratégico nagovernamentalidade contemporânea ao divulgar à população os riscos de problemas no desenvolvimento a que estão sujeitas as crianças nascidas em famílias pobres. Isso porque os supostos riscos descritos por esses especialistas precisam ser amplamente divulgados e anunciados, pois, como alerta Lemke (2014), é preciso convencer as pessoas de que o risco é real.

Para tanto, a expertise delimita um padrão de observáveis a respeito do que é considerado o desenvolvimento normal de uma criança e, ao mesmo tempo, afirma e constitui o que é diferente do padrão proposto (LEWIS, 1999; WONG, 2008). Aquilo que não está inserido nos referenciais é compreendido como risco. É nesse ponto que a autoridade dos experts econômicos ganha notoriedade (O’MALLEY, 1996). A eles é atribuído o papel de falar a verdade sobre as crianças para justificar as formas de intervenção que sobre elas e suas respectivas famílias serão exercidas, como forma de prevenir riscos.

Esse é o objetivo do trabalho desenvolvido pelos experts: ajustar, corrigir, modificar as formas de ser das crianças e transformálas em algo supostamente mais adequado aos princípios de uma vida futura produtiva em sociedade. Por essa razão, o interesse, conforme aponta Esping-Andersen (2007), está na potencialização do capital humano infantil, a partir de uma perspectiva educacional 
economicista, baseada em uma racionalidade política que procura incluir a todos. É esse interesse decorrente da expertise econômica que torna possível a proposição de programas de Educação Infantil a serem operacionalizados por países pobres.

As normas e os valores da expertise se tornam convincentes por causa da crença de que a infância à margem das condições de vida consideradas produtivas é um risco social que demanda acompanhamento, avaliação e intervenção (LUPTON, 1999; LEMKE, 2014). Nesse sentido, os excertos a seguir são ilustrativos do argumento desenvolvido.

[...] os programas de Educação Infantil mostram um retorno mais consistente para crianças carentes. Essas crianças são menos propensas a receber um desenvolvimento cognitivo e não cognitivo adequado em casa, e com menor probabilidade de serem matriculadas na Educação Infantil privada. Em segundo lugar, as crianças carentes têm probabilidade de entrar na escola com um déficit significativo. Por isso existem razões para se dedicar a elas e permitir que recuperem o atraso (EVANS; KOSEC, 2011, p. 8).

Os primeiros anos de vida de uma criança são cruciais para seu desenvolvimento. Desde o nascimento até os cinco anos de idade as crianças desenvolvem "capacidades fundamentais" sobre as quais o resto de seu desenvolvimento será construído. Assim como ambientes positivos e oportunidades podem levar crianças ao sucesso, o fracasso em fornecer essas oportunidades pode reduzir significativamente as perspectivas futuras (EVANS; KOSEC, 2011, p. 2).

As deficiências nesse início de desenvolvimento físico, linguístico, cognitivo e socioemocional comprometem seriamente a capacidade e a motivação para aprender dessas crianças pobres ao ingressarem na escola primária. À medida que crescem, essas crianças são mais propensas a ter mau desempenho escolar, a repetir de ano e a abandonar a escola do que aquelas cujas habilidades cognitivas e prontidão escolar global eram maiores ao ingressar na escola primária (NAUDEAU et al., 2011, p. 37).

Mediante a leitura, é possível observar que, com a interpelação do leitor, por meio do esclarecimento dos riscos a que estão sujeitas as crianças pobres de terem problemas no desenvolvimento, é definido a quem compete legislar sobre o risco nas diferentes esferas do fazer humano (LUHMANN, 2002). Os textos apresentados nos documentos obtêm seu efeito por meio da persuasão inerente às suas verdades, das ansiedades estimuladas por suas normas e das atrações exercidas pela imagem de infância futuramente produtiva que é ofertada, como se acompanha a seguir:

Uma análise de 2007 dos dados de crianças dos países em desenvolvimento revela que mais de 200 milhões de crianças menores de 5 anos estão expostas a múltiplos riscos que afetam negativamente o seu desenvolvimento (GRANTHAMMCGREGOR et al., 2007), e cujas consequências podem ser dramáticas. Aos 6 
anos de idade, as crianças de famílias menos abastadas e as crianças cujas mães têm baixa escolaridade têm ficado muito atrás de seus colegas de lares mais ricos ou mais escolarizados (NAUDEAU et al., 2011, p. 37).

Avaliações rigorosas de programas de Educação Infantil de alta qualidade têm demonstrado impactos de longo prazo na educação, redução da pobreza e de participação no crime. A evidência mais forte vem dos Estados Unidos, onde as avaliações de programas de Educação Infantil, como o programa High Scope Perry Preschool, o programa Abecedarian e o programa Chicago Child Parent, têm demonstrado impactos de longo prazo em uma ampla gama de resultados (EVANS; KOSEC, 2011, p. 4).

Como pode ser visto, é por meio da divulgação dos riscos e dos resultados potencialmente gerados a partir de avaliações dos programas de Educação Infantil que a expertise econômica se torna central à governamentalidade e ao processo de formação de certo tipo de capital humano (GADELHA, 2009). É a produção de conhecimentos chancelados cientificamente que fornece as diretrizes e as recomendações através das quais a população infantil pobre é comparada às normas do que é definido como desenvolvimento humano saudável e preparada, em longo prazo, para se tornar produtiva (MERRIEN, 2008).

Ao descrever a população infantil em posição de risco, a expertise rompe com a ideia de criança natural. Se determinadas crianças são caracterizadas como pertencentes a um grupo que representa risco, é em função da constituição de regimes de verdade que as narram nessa condição. Ao serem produzidos discursos sobre os riscos no desenvolvimento humano infantil possivelmente causados pela pobreza, são estabelecidas normas e classificações que descrevem quem são as crianças vulneráveis. Para tanto, conforme Wong (2008), tais crianças passam a ser tratadas como um fenômeno que precisa ser conhecido a partir de pesquisas, descrito e governado por meio da produção de conhecimentos.

Nessa direção, para que se efetivem as práticas de governamento, é preciso que governantes, educadores e famílias sejam continuamente interpelados, esclarecidos e orientados a respeito dos riscos que a pobreza pode causar na vida das crianças. Assim, para que sejam efetivadas determinadas práticas de produção de capital humano infantil, é necessária a contínua produção de risco no presente (EWALD, 1991).

Por essa via, outro aspecto importante nas pesquisas decorrentes da expertise econômica é a atribuição de um papel central ao cérebro infantil, no que diz respeito à possibilidade de desenvolvimento de habilidades (CUNHA et al., 2006; HECKMAN, 2008) promotoras de retorno econômico futuro. Nesse contexto, as neurociências, em confluência com a psicologia cognitiva, deixam de 
ser apenas práticas de laboratório e tornam-se um modelo explicativo do desenvolvimento infantil. Desse modo, de acordo com Rose (2013), o cérebro das crianças passa a ser considerado, no âmbito das análises econômicas, um rascunho sobre o qual podem ser feitas escolhas. Nesse estilo de pensamento da expertise econômica, o cérebro infantil é considerado um órgão plástico e flexível, sendo, portanto, passível de ter o seu rendimento potencializado a partir de intervenções educacionais precoces.

De acordo com Miller e Rose (2012), a teorização decorrente dessa expertise opera como um modo de tornar a existência da população infantil em situação de risco pensável, com base em técnicas de inscrição, notação e cálculo. Isso ocorre, segundo Ewald (1991, 2000), porque o risco precisa ser disciplinado. Disciplinar o risco significa prever as possibilidades de sua ocorrência, elencando ações adequadas para que ele seja controlado, como pode ser observado nos excertos que seguem.

Os atrasos de desenvolvimento antes dos 6 anos de idade são difíceis de compensar mais tarde na vida, porque a infância é um período particularmente importante na formação do cérebro. De fato, estudos neurológicos têm mostrado que as sinapses se desenvolvem rapidamente durante esse período, formando a base do funcionamento cognitivo e emocional para o resto da vida da criança. Por isso tanto a nutrição apropriada, especialmente desde a concepção até os 2 anos de idade, quanto a estimulação nos primeiros 5 anos de vida desempenham papel crítico no processo de formação e desenvolvimento cerebral, principalmente auxiliando na multiplicação de sinapses e no processo de mielinização, ambos essenciais para o normal funcionamento do sistema nervoso. Por outro lado, a falta de nutrição adequada e de estimulação nos primeiros anos pode levar a alterações dramáticas no desenvolvimento do cérebro (NAUDEAU et al., 2011, p. 17).

Muitas funções cerebrais são especialmente sensíveis a mudanças no início da vida e tornam-se menos plásticas ao longo do tempo. Na verdade, a maior parte do cérebro da criança é "conectada" nos primeiros cinco anos de vida, o que deixa pouco espaço para ajustes posteriores. Até mesmo funções que continuam a ter um alto grau de sensibilidade mais tarde na infância (por exemplo, a habilidade numérica e as habilidades sociais com os colegas) atingem seus picos de sensibilidade nos primeiros 4-5 anos de vida. Outras funções, como controle emocional e padrões de resposta habituais não só atingem o auge nos primeiros anos, mas em geral atingem um alto nível de estabilidade antes dos 5 anos. Isso sugere que tais padrões não podem ser facilmente modificados posteriormente, razão pela qual a estimulação precoce e as oportunidades de aprendizagem antes de ingressar na escola primária são essenciais (NAUDEAU et al., 2011, p. 38).

Por meio da leitura, é possível observar a centralidade que assume o cérebro infantil, constituindo o que Ehrenberg (2009) denomina sujeito cerebral. Trata-se de uma nova figura antropológica, através da qual se dissemina o argumento de que o cérebro é o único órgão do corpo 
necessário para definir a identidade de alguém. Nesse sentido, de acordo com Ortega e Zorzanelli (2010), o ser humano passa a ser definido pela propriedade ou qualidade de ser, e não apenas de ter um cérebro.

Desse modo, é importante esclarecer que a produção discursiva a respeito da centralidade do cérebro no desenvolvimento infantil faz parte de uma rede de discursos emergentes das neurociências e da psicologia cognitiva, na qual se fundamenta a expertise econômica (ROSE, 2013). O intuito de tal expertise é divulgar os benefícios decorrentes do investimento em capital humano infantil a partir da formação de sujeitos produtivos.

Por esse motivo, é ressaltada recorrentemente nos documentos analisados a relevância de serem investidos recursos financeiros em programas de Educação Infantil para crianças de 0 a 5 anos, com base na justificativa de que, com o tempo, o cérebro elimina os circuitos menos utilizados e fortalece os mais utilizados, aumentando a dificuldade de alterar comportamentos indesejados no decorrer da vida (HECKMAN; MASTEROV, 2004). Desse modo, conforme os analistas, torna-se fundamental intervir nos primeiros anos da criança, como forma de assegurar condições positivas de desenvolvimento e saúde ao longo da vida, uma vez que o cérebro é particularmente responsivo a experiências nesse período (HECKMAN, 2006; ARAÚJO, 2011).

Para os analistas econômicos, é fundamental identificar crianças que poderão estar sob a influência de fatores de risco. Conforme aponta Luhmann (2002), para cada risco produz-se a necessidade da criação de comissões técnicas responsáveis por sua avaliação. Nesse sentido, Evans e Kosec (2011) enfatizam a produtividade da realização de testes para a prevenção de riscos de problemas de desenvolvimento infantil e a avaliação de impactos de programas de Educação Infantil, como poderá ser observado nos próximos excertos. "O teste do desenvolvimento cognitivo e socioemocional das crianças pode desempenhar um papel importante na aferição da saúde geral do sistema de Educação Infantil, além de identificar crianças com necessidades especiais” (EVANS; KOSEC, 2011, p. 28).

Se o objetivo é avaliar a qualidade do sistema, então, testar uma amostra de estudantes do sistema pode ser suficiente e pode tornar os custos dos testes muito mais viáveis. Os resultados dos testes podem ser desvinculados dos identificadores de alunos específicos para proteger seu bem-estar. Ao mesmo tempo, muitos sistemas de avaliação nos Estados Unidos necessitam que as creches façam triagens para garantir que as crianças estão se desenvolvendo de forma adequada e para ver se serviços adicionais são necessários (EVANS; KOSEC, 2011, p. 29).

Uma vasta gama de instrumentos é usada em sistemas de avaliação nos Estados Unidos, mas os instrumentos mais indicados tendem a ter duas características em comum: 1) muitos foram projetados como ferramentas de triagem e não 
são medidas amplas de Desenvolvimento na Primeira Infância; 2) todos eles dependem de avaliações e relatórios dos pais ou dos educadores, em vez da avaliação direta com as crianças. Um dos mais usados é o questionário Ages e Stages ${ }^{9}$ (Idades e Fases), que recentemente foi traduzido e validado para uso no município do Rio de Janeiro (EVANS; KOSEC, 2011, p. 29).

Conforme afirma Moss (2011), a concepção de desenvolvimento infantil na qual se fundamentam os testes é linear, pois trabalha com um modelo de criança ideal. A lógica do desenvolvimento infantil adotada pelos analistas econômicos desconsidera que distintas culturas, antecedentes econômicos, características étnicas e religiosas, bem como os atravessamentos de gênero e de histórias individuais de vida, constroem diferentes experiências de ser criança e diferentes mundos da infância. Estes não podem ser pautados em práticas universais a serem desenvolvidas em todos os países. Logo, se o conhecimento produzido pela expertise econômica tem gozado de alta reputação e credibilidade, talvez seja porque a crescente expansão da governamentalidade neoliberal esteja cada vez mais constituindo o tempo em que vivemos (VEIGA-NETO, 2000).

\section{O INVESTIMENTO EM DPI COMO LEMA DA PRONTIDÃO PARA A ESCOLA E PARA A VIDA}

O campo de DPI, definido na Convenção das Nações Unidas sobre os Direitos da Criança, refere-se ao desenvolvimento dos domínios físico, cognitivo, linguístico e socioemocional infantil de 0 a 6 anos de idade, tendo em vista a prontidão para a escola e para a vida.

Os domínios de desenvolvimento definidos pelo DPI são descritos por meio de um processo contínuo e previsível de etapas a serem alcançadas por todas as crianças (NAUDEAU et al., 2011). Tal perspectiva de desenvolvimento se distancia de uma teoria contextualista em que o comportamento e as necessidades das crianças podem estar relacionados com adaptações ao presente.

De acordo com Heckman (2008), crianças que tiveram uma boa nutrição, acesso à saúde, estimulação adequada e que viveram em um ambiente familiar acolhedor serão adultos mais produtivos do que aquelas que não tiveram esses fatores. Para o autor, é importante investir nos primeiros anos de vida do ser humano, pois por mais tempo a sociedade poderá usufruir desses benefícios e maior será o período disponível para a recuperação desse investimento.

Desse modo, é possível perceber que a concepção de desenvolvimento humano utilizada para promover o DPI reflete um 
modelo econômico de investimento em capital humano. Os construtos teóricos desse modelo fundamentam-se em uma perspectiva universal de desenvolvimento infantil, a qual, segundo a crítica de Lewis (1999, p. 36), tem as seguintes características:

1. Desenvolvimento é mudança com uma direção, portanto tem um ponto de chegada. 2. Eventos anteriores estão ligados aos posteriores. 3. A mudança é gradual, em progressão lenta e cumulativa. 4. Eventos que ocorrem nos primeiros anos de nossas vidas produzem efeitos mais duradouros e significativos.

A partir da definição de desenvolvimento infantil apresentada, pode-se dizer que ela é semelhante ao modo como os autores dos documentos analisados descrevem as mudanças que ocorrem ao longo da vida das crianças. O desenvolvimento infantil é descrito de modo linear, evidenciando o desejo de controle que as ciências, as práticas da educação formal e, de modo correlato, a expertise econômica têm estabelecido atualmente sobre as crianças. Essa perspectiva de desenvolvimento, conforme Wong (2008), indica, de forma categórica, quem é a criança, o que ela pode ser, o que ela pode fazer e quais ações não são permitidas nesta ou naquela idade. Nessa linearidade em que é cartografado o desenvolvimento infantil, a trajetória é de mão única. Nela, não é possível o retorno a uma etapa anterior, nem a intersecção entre características e etapas próximas e distantes. A criança é concebida como um bloco monolítico, e avançar em linha reta é a única possibilidade de desenvolvimento "saudável" e "normal" (BURMAN, 1999).

Desse modo, nas análises econômicas, as crianças são significadas como seres humanos dependentes que se desenvolvem com base nos indicadores definidos por uma perspectiva de desenvolvimento linear. Resultados de pesquisas efetuadas no campo da psicologia cognitiva e das neurociências são evocados para justificar a trajetória do desenvolvimento da criança descrita nas publicações que defendem a intervenção precoce como modo de promoção do capital humano infantil (ARAÚJO, 2011). Conforme Penn (2002), resultados de estudos empíricos específicos no campo da psicologia são generalizados na construção de indicadores de desenvolvimento, no contexto dos programas de Educação Infantil, e divulgados como modelos a serem seguidos pelos países pobres.

Nesse sentido, o desenvolvimento infantil é descrito a partir da conexão entre um domínio de racionalidade e um regime particular de práticas, tendo em vista a produção dos cidadãos do futuro. Tal colocação poderá ser observada nos excertos transcritos a seguir:

O desenvolvimento físico é definido como uma taxa individual de crescimento, aptidão física, habilidades motoras finas, habilidades motoras grosseiras e capacidade de cuidar 
de si mesmo; esse desenvolvimento pode ser afetado pela presença de condições crônicas, como diabetes, deficiência física e desnutrição (NAUDEAU et al., 2011, p. 7).

O desenvolvimento cognitivo envolve progressos nas habilidades analíticas, de resolução de problemas mentais, memória e nas primeiras habilidades matemáticas. Em recém-nascidos e bebês, o desenvolvimento cognitivo precoce envolve a resolução de problemas, tais como aprender a empilhar ou guardar objetos, e as primeiras noções de aritmética, demonstradas por comportamentos tais como ordenar objetos e saber o que "um" ou "dois" de algo significa. Aos 3 anos de idade, as crianças devem ser capazes de resolver problemas simples e combinar cores e formas, assim como demonstrar ter consciência de conceitos como "mais" e "menos". Conforme as crianças se aproximam da idade escolar, o desenvolvimento cognitivo amplia seu alcance para o conhecimento precoce dos números, incluindo adição e subtração, e a familiaridade com as letras do alfabeto e letras impressas (NAUDEAU et al., 2011, p. 7).

O desenvolvimento da linguagem se manifesta inicialmente no recém-nascido pelos atos de balbuciar, apontar e gesticular, e depois pelo surgimento das primeiras palavras e frases enquanto bebê, até a explosão das palavras entre as idades de 2 e 3 anos. É importante notar que a capacidade de absorver a linguagem e distinguir sons surge por volta dos 9 meses de idade, muito antes que a criança possa realmente falar, o que indica que é de fundamental importância que os pais/cuidadores interajam verbalmente com as crianças desde o nascimento. Quando as crianças chegam à idade pré-escolar, os indicadores de desenvolvimento da linguagem incluem a produção e a compreensão de palavras, a capacidade de contar histórias, identificar letras e a intimidade e familiaridade com os livros (NAUDEAU et al., 2011, p. 8).

O desenvolvimento social e emocional nos primeiros 2 anos de vida gira em torno do relacionamento das crianças com os cuidadores, quando elas aprendem em que medida podem confiar naqueles ao seu redor para satisfazer as suas necessidades. $\mathrm{Na}$ idade pré-escolar, o desenvolvimento social e emocional se constrói sobre as aquisições anteriores e se expande para incluir a competência social, a gestão de comportamento, a percepção social, e capacidades de autocontrole (NAUDEAU et al., 2011, p. 8).

A leitura dos excertos possibilita destacar a presença de uma perspectiva linear de desenvolvimento infantil (BURMAN, 1999; LEWIS, 1999) com base no estereótipo da experiência humana dividida nos domínios: físico, linguístico, cognitivo e socioemocional. Esses domínios são criados como modo de objetivação da população infantil, a partir do qual são enumeradas as práticas que os adultos devem adotar no intuito de possibilitar que as crianças vençam os estágios previstos. Isso ocorre porque os autores dos documentos em análise se esforçam para encontrar padrões comuns a todas as crianças, desconsiderando diferenças individuais, idade, nível socioeconômico, etc.

Penn (2002) afirma que, em documentos produzidos pelo Banco Mundial, o entendimento é que os estágios de desenvolvimento infantil são semelhantes em todos os países, já que se defende a tese 
de que a "cultura" produz apenas pequenas variações no modo de vida das crianças. Por essa razão, conforme a autora, o padrão e as etapas de desenvolvimento infantil descritos em análises econômicas defendem a importância de que sejam implantados nos países pobres programas de Educação Infantil que incidam diretamente no desenvolvimento das crianças, para que possam ser obtidos os resultados desejados. Isso porque, para os economistas, na fase inicial da vida, as crianças apresentam características semelhantes, visto que se encontram no começo de seus processos de formação.

Para Heckman (2008), os investimentos em capital humano, além de reduzirem as desigualdades, reduzem também ou até mesmo eliminam o trade-off eficiência versus equidade, pois, de modo geral, esses investimentos são mais equitativos devido à semelhança das crianças nos seus primeiros anos de vida, independentemente de seu contexto cultural de origem. Nessa visão econômica, o objetivo principal do desenvolvimento da criança é produzir uma população adulta produtiva, favorecendo, dessa forma, a existência de comunidades mais fortes e economicamente prósperas (CUNHA; HECKMAN, 2011).

Nesse sentido, defende-se o argumento de que, durante o período configurado como janelas de oportunidades, o cérebro infantil apresenta uma maior facilidade em criar circuitos neuronais funcionais, se existirem experiências do meio positivas para a aquisição de competências. Tais janelas de oportunidades são divididas em quatro períodos: 1) in utero; 2) do nascimento aos 6 meses; 3) dos 7 meses aos 2 anos; 4) dos 3 aos 5 anos (NAUDEAU et al., 2011). Por essa razão, na perspectiva da governamentalidade, é importante dizer que, a partir da definição de domínios e de janelas de oportunidades para a intervenção no desenvolvimento infantil, são definidos parâmetros do que é considerado um desenvolvimento "normal" (BURMAN, 1999). Constituem-se, desse modo, as crianças advindas das famílias de baixa renda como uma população de risco, a qual precisa de intervenção para que desenvolva prontidão para a entrada na escola e para a vida.

Nessa lógica, Cunha et al. (2006) afirmam que o foco no planejamento de políticas voltadas para a Educação Infantil tem importância, pois, quanto mais equitativa for a educação inicial, menores serão as desigualdades futuras. Isso porque, conforme os autores, a educação desenvolve habilidades essenciais para que as crianças se tornem adultos economicamente eficientes. Para a realização de intervenções, são criados mecanismos, como os programas de DPI, que reúnem os fatores responsáveis pela produção 
do risco de atraso no desenvolvimento infantil antes da ocorrência de seus efeitos, possibilitando o planejamento de ações, a fim de administrá-lo e preveni-lo (ROSE, 2013).

\section{OS PROGRAMAS DE DPI E A GESTÃO DE RISCOS}

A governamentalidade como racionalidade que procura administrar as problemáticas da população traça estratégias cujo intuito é disciplinar a conduta dos indivíduos. Para que o governamento seja operacionalizado, é preciso ter a população como objeto de conhecimento, procurando estabelecer suas principais características, suas formas de comportamento, seus hábitos, suas crenças, suas formas de organização e até mesmo os limites e as possibilidades dessa massa de indivíduos enquanto seres biológicos e psicológicos (FOUCAULT, 2008b).

Desse modo, sustentados discursivamente como investimentos eficazes no desenvolvimento humano decorrentes de pesquisas estatísticas longitudinais desenvolvidas no cenário americano, os programas de DPI indicados nos documentos analisados operam como instrumentos de governamento da população. Através de tais programas, sob o lema da "prontidão escolar e da prontidão para a vida", emerge uma série de estratégias administrativas e preventivas relativas à gestão de fatores de risco (ROSE, 2013). Nessa perspectiva, conforme O’Malley (1996), o risco é considerado um elemento associado ao progresso social, o qual, em vez de ser minimizado, é gerido enquanto recurso econômico para o aperfeiçoamento da sociedade, como poderá ser visualizado a seguir.

As intervenções nos primeiros anos de vida têm o potencial de compensar tendências negativas, proporcionando às crianças menores mais oportunidades e melhores resultados em termos de acesso à educação, qualidade da aprendizagem, crescimento físico, saúde e produtividade. Investir em DPI tem efeitos em cascata sobre a vida dos beneficiários, essas intervenções estão entre os investimentos mais custo-efetivos que um país pode fazer para o desenvolvimento humano e a formação de capital humano da nação (NAUDEAU et al., 2011, p. 6).

Comportamentos de alto risco comum às crianças e jovens incluem fumar, comportamento sexual de risco, uso de drogas, dependência química e atividades criminosa e violenta. Tais comportamentos reduzem a chance de uma criança fazer uma transição bem-sucedida para a vida adulta e aumentam a probabilidade de resultados negativos, tais como doenças, desemprego, gravidez na adolescência, doenças sexualmente transmissíveis, vícios, reclusão e exclusão social. Programas que melhoram as habilidades cognitivas e socioemocionais melhoram a capacidade das crianças de autorregularem seus comportamentos e emoções (NAUDEAU et al., 2011, p. 19). 
Como pode ser observado, os fatores de risco são traduzidos em programas que destacam uma utopia higienista à segurança e à prosperidade da população, através do exercício da autoridade sobre as pessoas relativamente às suas práticas e crenças (EWALD, 1991; MILLER; ROSE, 2012). Isso se deve à natureza probabilística da identificação de fatores de risco, que conduz ao planejamento de estratégias preventivas baseadas em programas de DPI.

Nos Estados Unidos, por exemplo, conforme Penn (2002), existe um acervo de pesquisas estatísticas de cunho econômico sobre a eficiência de programas de Educação Infantil. Trata-se de pesquisas longitudinais, centradas na avaliação do impacto da frequência à escola sobre o desempenho cognitivo e afetivo das crianças (ARAÚJO, 2011). Tais pesquisas, por terem sido realizadas em um período de mais de 20 anos, foram amplamente divulgadas, e seus dados têm sido utilizados como fundamentação dos argumentos dos analistas econômicos sobre a eficácia dos programas de DPI.

A divulgação dessas pesquisas, conforme Viana (2012), teve as suas condições de emergência no início da década de 1980, ocasião em que o Consortium of Longitudinal Studies, fundado nos Estados Unidos em 1975, publicou um volume com 14 pesquisas de acompanhamento de crianças egressas de programas de Educação Infantil da década de 1960. Na época da publicação, as crianças participantes, em sua maioria negras e pobres, estavam com idades entre 8 e 18 anos e haviam frequentando diferentes tipos de programas compensatórios.

No caso dos documentos analisados, quatro pesquisas americanas são recorrentemente citadas como exemplos a serem seguidos para a implantação de programas de DPI com foco na Educação Infantil. Programas como Early Head Start (EHS), Chicago Child Parent Centers (CPC), Abecedarian Program e High/Scope Perry Preschool são descritos como importantes campos de pesquisa. Os referidos programas focalizaram crianças em desvantagens socioeconômicas, como pais com baixos níveis de escolaridade, renda, capacidade cognitiva, níveis elevados de comportamentos patológicos, entre outros fatores considerados pelos analistas como de risco (VIANA, 2012).

O programa Early Head Start, lançado na década de 1960 nos Estados Unidos, consistiu em uma linha de financiamento federal a programas de Educação Infantil diversificados localmente, que se caracterizam por atender a crianças pobres. Conforme Naudeau et al. (2011), os 17 programas de pesquisa incluíram: 1) quatro programas baseados em centros, que prestaram serviços de desenvolvimento infantil em creches, juntamente com a educação dos pais; 2) sete programas domiciliares, que promoveram serviços 
de desenvolvimento infantil por meio de visitas domiciliares semanais e pelo menos duas sessões ao mês de atividades de socialização em grupo entre pais e crianças para cada família; 3) seis programas de abordagem mista, que prestaram serviços domiciliares ou em centros, tanto para cada família individualmente quanto para várias famílias simultaneamente (EVANS; KOSEC, 2011).

O programa Chicago Child Parent Centers (CPC) caracterizouse como uma proposta de meio período, durante o ano escolar, em escolas públicas de Chicago. O programa iniciou efetivamente em 1967; porém, os dados para a pesquisa começaram a ser coletados somente a partir da década de 1980 . As crianças entravam no programa com 3 ou 4 anos e permaneciam por um período máximo de seis anos. A amostra foi composta por um grupo de 989 crianças, que foram acompanhadas até os 21 anos de idade.

$\mathrm{O}$ Abecedarian Program atendia às crianças em tempo integral, desde os primeiros meses de vida. As 111 crianças que entraram no programa entre 1972 e 1977 foram acompanhadas até os 21 anos de idade. Esse foi um programa experimental, no qual foram formados quatro grupos para avaliação, constituídos por crianças que: 1) não sofreram nenhum tipo de intervenção pelo programa; 2) sofreram intervenção até os 5 anos de idade; 3) sofreram intervenção dos 5 aos 8 anos; 4) sofreram intervenção desde os primeiros meses de vida até os 8 anos. A operacionalização do programa consistiu em aulas diárias, em tempo integral, durante os 12 meses do ano, complementadas por visitas regulares dos professores às casas das crianças durante os três primeiros anos do ensino primário (EVANS; KOSEC, 2011).

O High/Scope Perry Preschool foi um programa experimental de meio período realizado em escolas públicas no Michigan que se tornou bastante conhecido pelo grande público devido à sua extensa divulgação em análises econômicas (VIANA, 2012). Trata-se de um programa de Educação Infantil que adotou o currículo desenvolvido pela Fundação High/Scope, em Ypsilanti, Michigan, e que atendeu a 58 crianças e acompanhou outras 65 como comparação. As crianças entraram no programa entre 1961 e 1965 com 3 ou 4 anos de idade e permaneceram por dois anos. As crianças do grupo experimental frequentaram o programa por dois anos, durante duas horas e meia por dia, complementadas com uma visita domiciliar semanal realizada pelo professor. O acompanhamento ocorreu anualmente até os 15 anos de idade e, depois, aos 18, 27 e 40 anos de idade. Os egressos foram acompanhados por mais de 20 anos, e sua trajetória de vida, escolar e profissional, foi comparada com o grupo de controle. 
Conforme Viana (2012), os resultados dos programas evidenciaram que intervenções precoces no desenvolvimento de crianças em desvantagem socioeconômica são eficientes em termos de desenvolvimento de habilidades, aumento de nota em testes cognitivos, aumento da probabilidade de completar o ciclo educacional básico, redução da retenção e de tempo em classes especiais de educação, diminuição da criminalidade, da delinquência e da gravidez precoce. Por outro lado, segundo o dito pela referida autora sobre os resultados dos programas, é importante refletir que, ao ser descrita e quantificada uma diversidade de realidades com base em programas de DPI, são extintas as individualidades e os resultados são superdimensionados tendo em vista a construção de processos de individualização (ROSE, 2013).

Corroborando o argumento, Penn (2002) critica a generalização das pesquisas decorrentes de programas de DPI realizadas pelos norte-americanos pelo fato de elas serem transformadas em modelos prescritivos de investimento no desenvolvimento infantil a serem seguidos pelos países pobres a partir de onerosos financiamentos. Para a autora, os analistas divulgam a ideia de que basta que os profissionais encontrem o programa certo para os países e o tipo correto de intervenção a ser usado com as crianças para que o retorno econômico seja garantido, através do aumento da renda nacional e da correlata redução dos níveis de pobreza. Tomar os programas americanos, decorrentes das pesquisas realizadas na década de 1960, como modelo para a implantação de programas nos países em desenvolvimento é desconsiderar as diferenças relativas aos contextos culturais nos quais se encontram as crianças alvo dos programas.

\section{CONSIDERACְÕES FINAIS}

A infância das crianças oriundas de famílias de baixa renda tem constituído uma figura central no governamento das populações. Conforme Moss (2011), o cerne dessa problemática ocorre via processo educativo. Contudo, mais do que um objeto exclusivo da educação, a infância é interpelada e produzida por diferentes âmbitos disciplinares, o que tem estimulado uma produção cada vez maior de saberes sobre ela.

A premissa é que intervenções educacionais planejadas qualificam o capital humano da criança pobre e elevam a produtividade do futuro trabalhador (HECKMAN, 2006, 2008). Dessa forma, conforme Viana (2012), em termos agregados, o investimento no capital humano infantil nos países em desenvolvimento é visto como uma via de combate à pobreza, de distribuição de renda e 
de redução de desemprego. Para tanto, são divulgados outros benefícios desse tipo de investimento em longo prazo, como, por exemplo, empregabilidade, baixas taxas de fertilidade e menores taxas de crime entre os adultos oriundos de famílias de baixa renda que participaram de algum tipo de programa durante a infância.

Para os analistas econômicos (HECKMAN; MASTEROV, 2004), o objetivo da infância é fazer a criança se tornar o cidadão produtivo e empreendedor do futuro. Por essa razão, essa expertise promove e dissemina o discurso de que o baixo investimento em capital humano é mais acentuado nas famílias pobres. O argumento é que indivíduos menos escolarizados tendem a ser pobres no futuro e que, por esse motivo, investem menos na educação de seus filhos. $\mathrm{O}$ alerta presente nos documentos analisados é o de que existe um risco de perpetuação do ciclo vicioso intergeracional da pobreza, no qual pais pobres produzem filhos pobres, gerando gastos desnecessários para os países. O acento é no discurso de que crianças pobres que forem instruídas precocemente estarão mais aptas a contribuir com a sociedade, de tal forma que se gere um ciclo de efeitos positivos não somente para elas próprias, mas também para a sociedade e para o desenvolvimento do país (MARQUEZ, 2006).

Logo, o que pode ser feito diante das discussões apresentadas no decorrer do artigo? Ainda é cedo para analisarmos os efeitos políticos do processo de investimento em capital humano infantil em nosso país. Mas é certo que os pesquisadores do campo da Educação Infantil precisam estar atentos, pois as análises econômicas, a partir de uma lógica baseada na concorrência, na eficiência e no gerenciamento de riscos (FOUCAULT, 2008a, 2008b), engendram saberes que encontram ressonâncias no processo de escolarização precoce da infância. Não por acaso houve uma ampliação do Ensino Fundamental, foi tornada obrigatória a Educação Infantil aos quatro anos de idade, o desenvolvimento das crianças de zero a cinco anos matriculadas no Rio de Janeiro foi aferido através de testagens psicométricas (ASQ3) e proliferam-se cada vez mais programas voltados para a educação das famílias em relação aos cuidados que devem ter com as crianças a partir do nascimento.

Os indícios apresentados evidenciam que contemporaneamente o investimento na formação do cidadão do futuro é muito mais presente em nosso meio do que ousamos imaginar. O desenvolvimento da prontidão das crianças para a escola e para a vida não é apenas um slogan econômico, mas um imperativo que tem sido traduzido em políticas de escolarização da infância contemporânea. 


\section{REFERÊNCIAS}

ARAÚJO, Aloísio. Aprendizagem infantil: uma abordagem da neurociência, economia e psicologia cognitiva. Rio de Janeiro: Academia Brasileira de Ciências, 2011.

BUENO, Cristiane Aparecida Ribeiro. As proposições do Banco Mundial para as políticas de Educação Infantil no Brasil (1990-2010). 2010. 140 f. Dissertação (Mestrado em Educação) - Programa de Pós-Graduação em Educação, Universidade Estadual do Oeste do Paraná, Cascavel, 2010.

BURMAN, Erica. La desconstrucción de la psicologia evolutiva. Madrid: Visor, 1999.

CUNHA, Flavio et al. Interpreting the Evidence on Life Cycle Skill Formation. In: HANUSHEK, E. A.; WELCH, F. (Ed.). Handbook of the Economics of Education. v. 1. n. 1. Amsterdam: North-Holland, 2006. p. 698-747.

CUNHA, Flávio; HECKMAN, J. James. Capital Humano. In: ARAÚJO, A. (Coord.). Aprendizagem infantil: uma abordagem da neurociência, economia e psicologia cognitiva. Rio de Janeiro: Academia Brasileira de Ciências, 2011. p. 9-32.

CUNHA, Flávio; HECKMAN, J. James. Formulating, Identifyng and Estimating the Technology of Cognitive and Noncognitive Skill Formation. Journal of Human Resources, Chicago, v. 43, n. 4, p.738-782, 2008.

CUNHA, Flávio; HECKMAN, J. James. The Economics and Psychology of Inequality and Human Development. NBER Working Paper 14695, Cambridge, MA, National Bureau of Economic Research, p. 1-63, 2009.

CUNHA, Flávio; HECKMAN, J. James. The Technology of Skill Formation. American Economic Review, Nova York, v. 97, n. 2, p. 31-47, 2007.

DEAN, Mitchell. Critical and effective histories: Foucault's methods and historical sociology. London: Routledge, 1997.

DEAN, Mitchell. Governmentality: power and rule in modern society. London: Sage, 1999. p. 9-27.

EHRENBERG, Alain. O sujeito cerebral. Tradução de Marianna Oliveira e Monah Winograd. Psicologia clínica, Rio de Janeiro, v. 21, n. 1, p. 187-213, 2009.

ESPING-ANDERSEN, G. Investing in children and their life chance. Barcelona: Universitat Pompeu Fabra, 2007.

EVANS, David K.; KOSEC, Katrina. Educação Infantil: Programas para a Geração Mais Importante do Brasil. Washington, DC: The World Bank, 2011; São Paulo: Fundação Maria Cecília Souto Vidigal, 2011.

EWALD, François. Foucault: a norma e o direito. 2. ed. Lisboa: Vega, 2000.

EWALD, François. Insurance and risk. In: BURCHEL, G.; GORDON, C.; MILLER, P. (Ed.). The Foucault effect: studies in governmentality. Chicago: The University of Chicago, 1991. p. 197-210.

FIMYAR, Olena. Governamentalidade como ferramenta conceitual na pesquisa de políticas educacionais. Educação e Realidade, Porto Alegre, v. 34, n. 2, p. 35-56, maio/ago. 2009.

FOUCAULT, Michel. O Nascimento da Biopolítica. São Paulo: Martins Fontes, 2008a.

FOUCAULT, Michel. Segurança, Território, População. São Paulo: Martins Fontes, 2008b.

GADELHA, Sylvio. Governamentalidade neoliberal, Teoria do Capital Humano e Empreendedorismo. Educação e Realidade, Porto Alegre, v. 34, n. 2, p. 171-186, 2009. 
GORDON, Colin. Governmental rationality: an introduction. In: BURCHEL, G.; GORDON, C.; MILLER, P. (Ed.). The Foucault effect: studies in governmentality. Chicago: The University of Chicago, 1991. p. 1-50.

GOUVÊA, Maria Cristina Soares; GERKEN, Carlos Henrique de Souza. Desenvolvimento Humano: história, conceitos e polêmicas. São Paulo: Cortez, 2010.

HECKMAN, J. James. Investing in disadvantaged young children is an economically efficient policy. Nova York: [s.n.], 2006. Forum on "Building the economic case for investing in preschool".

HECKMAN, J. James. Schools, skills and synapses. Economic Inquiry, Oregon City, v. 46, n. 3, p. 298-324, 2008.

HECKMAN, J. James; MASTEROV, Dimitriy. The productivity argument for investing in young children. Chicago: University of Chicago, 2004.

LEMKE, Thomas. Os riscos da segurança: liberalismo, biopolítica e medo. In: VACARRO, Salvo; AVELINO, Nildo (Org.). Governamentalidade: segurança. São Paulo: Intermeios, 2014. p. 105-128.

LEWIS, Michael. Alterando o destino: por que o passado não prediz o futuro. Campinas, São Paulo: Moderna, 1999.

LÓPEZ-RUIZ, Osvaldo. Os executivos das transnacionais e o novo espírito do capitalismo: capital humano e empreendedorismo como valores sociais. Rio Janeiro: Azougue Editorial, 2007.

LUHMANN, Niklas. El concepto de riesgo. In: GIDDENS, Anthony et al. Las consecuencias perversas de la Modernidad. Barcelona: Anthropos, 2002. p. 123-156.

LUPTON, Deborah. Risk. Londres: Routledge, 1999.

MARQUEZ, Christine Garrido. O Banco Mundial e a Educação Infantil no Brasil. 2006. 213 f. Dissertação (Mestrado em Educação) - Programa de Pós-Graduação em Educação, Universidade Federal de Goiás, Goiânia, 2006.

MERRIEN, François-Xavier. Du néolibéralisme à la nouvelle gouvernance libérale. In: GIRAUD, Olivier; WARIN, Philipe. Politiques Publiques et Democratie. Paris: La Découverte/Pacte, 2008. p. 50-64.

MILLER, Peter; ROSE, Nikolas. Governando o presente: gerenciamento da vida econômica, social e pessoal. São Paulo: Paulus, 2012.

MOSS, Peter. Qual o futuro da relação entre Educação Infantil e ensino obrigatório? Cadernos de Pesquisa, São Paulo, v. 41, p. 142-159, jan./abr. 2011.

NAUDEAU, Sophie et al. Como investir na Primeira Infância: um guia para a discussão de políticas e a preparação de Projetos de Desenvolvimento da Primeira Infância. Washington, DC: The World Bank, 2010; São Paulo: Singular, 2011.

O' MALLEY, Pat. Risk and responsability. In: BARRY, Andrew; OSBORNE, Thomas; ROSE, Nikolas (Ed.). Foucault and political reason: liberalism, neoliberalism and rationalities of government. Chicago: The University of Chicago Press, 1996. p. 189-207.

ORTEGA, Francisco. Neurociências, neurocultura e autoajuda cerebral. Interface: comunicação, saúde, educação, v. 13, p. 247-260, out./dez. 2009.

ORTEGA, Francisco; ZORZANELLI, Rafaela. Corpo em evidência: a ciência e a redefinição do humano. Rio de Janeiro: Civilização Brasileira, 2010.

PENN, Helen. Primeira infância: a visão do Banco Mundial. Cadernos de Pesquisa, São Paulo, v. 115, n. 2, p. 7-24, 2002. 
ROSE, Nikolas. A política da própria vida: biomedicina, poder e subjetividade no século XXI. São Paulo: Paulus, 2013.

SHORE, Cris; WRIGHT, Susan. Antropology of Policy: critical perspectives on governance and power. London: Routledge, 1997.

VEIGA-NETO, Alfredo. Educação e governamentalidade neoliberal: novos dispositivos, novas subjetividades. In: PORTOCARRERO, Vera; CASTELO BRANCO, Guilherme (Orgs.). Retratos de Foucault. Rio de Janeiro: Nau, 2000. p. 179-217.

VEIGA-NETO, Alfredo. Governo ou governamento. Currículo sem fronteiras, São Paulo, v. 5, n. 2, p. 79-85, jul./dez. 2005.

VIANA, Iara Azevedo Vitelli. Investimento produtivo em educação no Brasil: Educação Infantil para crianças pobres. 2012. 123 f. Dissertação (Mestrado em Estudos Populacionais e Pesquisas Sociais) - Escola Nacional de Ciências Estatísticas, Instituto Brasileiro de Geografia e Estatística, Rio de Janeiro, 2012.

WONG, James. Paradoxo de capacidade e poder: ontologia crítica e o modelo de desenvolvimento da infância. In: PETERS, Michael A.; BESLEY, Tina (Orgs.). Por que Foucault? Novas diretrizes para a pesquisa educacional. Porto Alegre: Artes Médicas, 2008. p. 81-99.

\section{NOTAS}

${ }^{1}$ Desenvolvimento na Primeira Infância (DPI) se refere a todas as atividades destinadas a promover o desenvolvimento cognitivo, emocional e comportamental em crianças com idade entre zero e cinco anos.

${ }^{2}$ Conforme López-Ruiz (2007, p. 183), o capital humano pode ser entendido como "um conjunto de capacidades, destrezas e talentos que, em função do avanço do capitalismo, tornou-se valor de troca".

${ }^{3} \mathrm{O}$ Banco Mundial (BM) tem um papel importante na fundamentação de políticas, pois sua missão é combater a pobreza e promover o desenvolvimento social e econômico dos países em desenvolvimento por meio de empréstimos, assessoramento às políticas, assistência técnica e serviços de intercâmbio de conhecimento.

${ }^{4} \mathrm{O}$ documento escrito por Sophie Naudeau, Naoko Kataoka, Alexandria Valerio, Michele J. Neuman e Leslie Kennedy Elder, consultores do Banco Mundial, apresenta um estado da arte sobre o campo do DPI. A tônica do documento produzido pelo Banco Mundial fundamentase no argumento de que os investimentos em DPI, em curto prazo, podem ser traduzidos em economia considerável de custos e em ganhos de eficiência nos setores de saúde e educação. O documento é endereçado aos governos, aos parceiros de desenvolvimento e à sociedade civil, e nele são apresentados os benefícios de se investir na primeira infância e as opções existentes para a criação de programas nos países em desenvolvimento.

${ }^{5}$ Organizado por David K. Evans e Katrina Kosec, analistas responsáveis por políticas de desenvolvimento da primeira infância, trata-se de um documento do Banco Mundial, traduzido e editado pela Fundação Maria Cecília Souto Vidigal. O documento foi amplamente divulgado no Brasil como uma ferramenta de trabalho para gestores públicos da área da educação, no intuito de esclarecer sobre estratégias eficazes que garantam o acesso de todas as crianças brasileiras aos benefícios da creche e da pré-escola para o ingresso na vida escolar em igualdade de condições. ${ }^{6}$ A partir da leitura de Veiga-Neto (2005), o termo governamento será utilizado, em vez de governo, nos casos em que estiver sendo tratada a questão da ação ou do ato de governar. 
${ }^{7}$ Esclareço que a discussão apresentada no artigo não é contrária ao direcionamento de mais recursos para a primeira infância. O que se problematiza é o viés economicista dos argumentos utilizados pelos autores dos documentos analisados para fundamentar a justificativa da necessidade de investimento na primeira infância, o que, por vezes, se apoia em estigmas referentes às crianças pobres e suas famílias.

${ }^{8}$ James Heckman é professor de Economia da Universidade de Chicago e professor de Ciências e Sociedade da Universidade de Dublin. Foi ganhador do prêmio Nobel de Economia em 2000 pelo trabalho na área de econometria e microeconomia. É pesquisador da área de Economia e possui a Fundação Heckman Equation, a qual busca disseminar os valores do investimento em Educação Infantil.

${ }^{9} \mathrm{Em}$ 2011, o teste foi realizado com 46 mil crianças de creches municipais e conveniadas da Secretaria Municipal de Educação do Rio de Janeiro, através de uma parceria com a Secretaria de Assuntos Estratégicos da Presidência (SAE).

Recebido: 16/01/2015

Aprovado: 17/06/2015

Contato:

Avenida Dom João Hoffmann, 313, Bairro Fátima (Junto ao Seminário Nossa Senhora de Fátima) Erechim |RS|Brasil

CEP: 99.700-000 
